\title{
A Well-Played Life: Discernment as the Constitutive Building Block of Selfless Leadership
}

\author{
Stephan Joubert
}

\begin{abstract}
Selfless leadership is a full-time calling, and a summons to be of service to others. It is a vocation, not as a position of power or an opportunity for selfenhancement. Selfless leaders know that discernment is not just another useful tool in the ever-expanding leadership toolkit to make their organisations more profitable, streamlined, or desirable. It is a gift, but also a learned ability to think, desire, know, feel, choose and do what is right for the present moment, and to influence future circumstances for the welfare and common good of others. Discernment is a habitual ability to read "the signs of the times" wisely and to act thereupon with clarity, wisdom and soberness. At the same time selfless leaders deliberately choose to focus on the potential, abilities, strengths and gifts of people in their organisation and on how to harness them to the best of their abilities, as well as to the advantage of their organisation. Just as any editor would ensure that an author produces the best possible manuscript by assisting him/her through all the phases of writing and rewriting, selfless leaders assist those within their spheres of leadership to become the best authors of their own and their organisation's stories. Their fine-tuned ability to discern the right paths to follow in planned and unplanned ways create safe spaces for good decisions, relational growth, creativity, the right kind of profitability, and healthy relationships.
\end{abstract}

\section{Shifting to Interactive, Process-Oriented Forms of Leadership}

In the previous century, those taken-for-granted assumptions regarding leadership such as that leaders should always be put on the centre stage, or that leadership is a function of a position are challenged from various angles nowadays. There is a clear shift away from the idea that officially appointed leaders are singlehandedly responsible for "engineering" the right working conditions and social environments in

\footnotetext{
S. Joubert $(\bowtie)$

Contemporary Ecclesiology, University of the Free State, Bloemfontein, South Africa

e-mail: stephan@ekerk.org
} 
order to enhance expected outcomes towards leadership as a process. More correctly, relational processes, or series of such interaction processes, which are co-produced by leaders and followers engaged in various relations of "mutuality," have now become prominent (cf. Karp 2013, pp. 17-18; Vlachoutsicos 2011, p. 124).

People can no longer be viewed as "human machines," nor should they be controlled by leaders and/or managers "to perform with the same efficiency and predictability" as machines (Wheatley 2007, p. 19). From this perspective, themes such as social capital, social awareness, as well as emotional and social intelligence have become part and parcel of the vocabulary and the theoretical jargon of new approaches to leadership. Individualised leadership, with a strong emphasis on highquality reciprocal relationships between leaders and followers, is more than ever significant. Within such relationships, leaders, according to Van Dierendonck and Driehuizen (2015, p. 103ff.), should provide their colleagues with a sense of selfworth, whereas the colleagues should reciprocate by providing satisfactory performance and outcomes mutually agreed upon.

Recent transformational approaches to leadership, while sometimes still reflecting persistent undertones of heroism inherent in the classic ideal of that one significant individual leader at the top, have begun to shift their emphasis in the direction of leaders' effects on their followers' organisational commitments (cf. Avolio et al. 2009; Chan and Mak 2014). Nowadays, the focus on subordinates' personal and professional ambitions, as well as their striving for success and achievement, are understood in terms of leaders' sustained efforts at, among others, their followers' "intellectual stimulation, idealized influence, inspirational motivation, and individual consideration" (Holstad et al. 2013, p. 270). Thus, at present, it is all about authentic leadership, ranging from multi-faceted processes of "essentialising" leaders' selves to an emphasis on leaders' "self-awareness, relational transparency, balanced processing of information, and internalized moral perspective" (Alok 2014, p. 268; cf. also Avolio and Gardner 2005). At the same time, the nature and characteristics of followership is more important than ever. In this regard, Kellerman's (2008, p. xxi) influential research on followership as "a relationship between subordinates and superiors and a response of the former to the latter" has been expanded to include the characteristics, predispositions and attitudes of followers, their preferences of leadership styles, and so forth (cf. Alok 2014).

Hogg's (2001, p. 185) assertion that "leaders exist because of followers and followers exist because of leaders" may represent the current emphasis on the symbiotic relationships between followers and leaders as a process of mutual influence. In order to make this transition from old ways of regarding an organisation "as an imposed structure, plan, design, or role" to a new world where organisation "arises from the interactions and needs of individuals who have decided to come together" (Wheatley 2007, p. 26), leaders urgently need new narratives derived from an entirely new understanding of self, others and reality. 


\section{Leadership as a Summons, a Calling}

Once you have reached that proverbial fork in the road, there is only one option available, left or right, except if your name is Yogi Berra. This famous American baseball player once remarked: "When you get to a fork in the road, take it!" At least he is right on one crucial point: you have to take some form of action when you have reached a crossroad. The ancient Greeks considered forks in the road so significant that they even had a specific goddess called Hekate who presided over them. Apart from guarding the graves by roadsides and the entrance to Hades (that is, the underworld), Hekate also protected crossroads. Women, in particular, relied on her guidance and wisdom when they reached certain "fork-road" stages in their lives (cf. Agha-Jaffar 2002, p. 77).

Making the right choices at those perilous crossroads in the life of any organisation is what leadership is all about, some would say. The popular leadership guru, John Maxwell, even states that approximately 95\% of the decisions CEOs make could also be made by any intelligent high-school graduate. They get paid for the remaining 5\%. Those are the tough calls, and the way in which leaders handle them is what separates them from everyone else (cf. http://www.execleadership.com/880/ 3-signs-youre-facing-a-tough-call.html). Still, effective leaders also know that it is not simply about the good choices. Indeed, these do matter, but leadership entails more than choices, positions, titles, power, successful enterprises, or bigger profits. Leadership is also about a "well-played" life (cf. Sweet 2014), one that is lived selflessly to the advantage of others within one's sphere of influence. Leaders who are "summoned to lead and to serve" in this manner do so from the heart, not merely from the mind. They never lead as part of their job description; they do so from their inner conviction.

At its core, leadership is deeply spiritual. Leadership is a full-time calling, a summons to be of service to others. It is a vocation, not a position of power or an opportunity for self-enhancement. A selfless leader's life would be miserable and unfocused if s/he did not respond to, and pursue this lifelong calling to serve. Over against the ambitious, majestic dreams of talented individualistic leaders, selfless leaders do not follow carefully scripted career paths in order to attain financial benefits or personal fame at the expense of others. They follow a lifelong vocation. Rather, their vocation chooses them. They are summoned to lead (cf. Sweet 2004); they are called! In fact, they have no choice in the matter. They know that such a calling of selfless service goes against the grain of the prevailing contemporary business culture, but they have no other option but to cultivate their gift and trained ability of discernment in order to be of service to others in their organisations.

Selfless leadership is not only a platform to help shape, but also a garden to help grow the lives of those within a leader's field of influence (cf. also Davenport 2015). It is an ongoing interactive process of assisting others in crossing those fixed mental and physical boundaries, which their social environments might have established in terms of the rules of business, the nature of competition, the tyranny of everincreasing profits, or the selfishness of winning at all costs. Discernment is a 
prerequisite to step up to this type of leadership. It also requires a profound shift in understanding what leadership is all about. More to the point, it entails a metanoia of sorts, one that will lead to a lifelong investment in personal character growth and the social upliftment of others.

\section{The "metanoetic" Nature of Selfless Leadership}

Although the Greek term metanoia is mostly used to signify religious conversions, this term means more than a moral repentance, or a revisiting of the pains and wrongdoings of the past. As a matter of fact, metanoia probably never signified a moral turnabout by sinners based on fear of divine punishment, but rather a change of heart and mind, a border-crossing experience that brings one to a fresh understanding of reality (cf. Joubert 2013, p. 122). Through metanoia "one becomes what

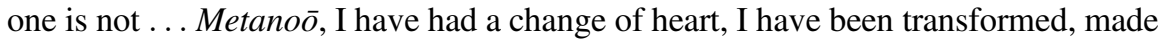
into something new ..." (Caputo 1999, p. 213). When using metanoia in terms of Jesus' new understanding of the concept, Moore (2009, p. 37) describes in detail the challenges posed by a metanoetic change of heart and mind: “. . one of the most difficult things to do is to change the way you imagine your place in life. Nothing is more challenging. On the other hand, once this takes place, nothing could be more vitalizing. Truly, it's as if you are born a second time. Your eyes open to a different world ... Metanoia comes at a great cost. You are to give up an understanding of life that has been in place for a long time."

Leaders have crossed the divide from old leadership paradigms, where their identity is determined by cultures that are explicitly or implicitly linked to control over others and sometimes even to the reduction of subordinates" "working selves to disposable pieces of furniture" (Harding 2014, p. 409). They are now part of a subversive new reality where selflessness is the norm. This shift requires nothing less than a personal metanoia. No, this shift is not a regression into a weak, laissez-faire form of leadership without any rules or boundaries. To the contrary, selfless leadership is strong and focused. Such leaders deliberately choose to curb their selfish egos, share power and use their influence to the advantage, growth and development of others. As an ongoing process of personal metamorphosis, such a shift of mind and heart facilitates new forms of "complexity leadership, where leaders turn into sages who create fluid new structures to facilitate trusting relationships, and a new culture of respect in which followers/workers/subordinates thrive as they are given permission to work and operate in their respective flow states" (Joubert 2013, p. 218). ${ }^{1}$

\footnotetext{
1“"Csíkszentmihályi is well known for his research on flow states, as a reference to any person's deep concentration and complete absorption with an activity at hand. This causes ... the person in flow not only forgets his or her problems, but loses temporarily the awareness of self that in normal life often intrudes in consciousness, and causes psychic energy to be diverted from what needs to be done (Csíkszentmihályi 1988, p. 33). This flow state is an optimal state of intrinsic motivation,
} 


\section{The Character of Selfless Leaders Is Grown in the Right Fertile Soil}

Character is the matrix of internalised beliefs, norms and values that define and direct a person. According to Hauerwas (1983, p. 39), "character is not merely the result of our choices, but rather the form our agency takes through our beliefs and intentions ... character is not a surface manifestation of some deeper reality called the 'self'. We are our character." Elsewhere, Hauerwas (1975, p. 203) mentions that "nothing is more nearly at the 'heart' of who we are than our character. It is our character that determines the primary orientation and direction which we embody through our beliefs and actions."

Character is not innate or automatic, as Brooks (2015) correctly argues. A strong moral character, which flows from a metanoia or a radical change in one's understanding of reality and which is expressed in a life of selfless service, has to be nurtured and cultivated. It has to be grown with both artistry and effort. As the English novelist James A. Froude would say: "You cannot dream yourself into character, you must hammer and forge one for yourself." Character needs the right fertile soil in which to grow. The fertilizers for this soil include:

(a) An unquenched curiosity, combined with a lifelong passion for learning;

(b) A child-like second naïveté;

(c) A strong sense of justice combined with deep empathy for others, as well as

(d) Ruthless honesty about personal blind spots and weaknesses.

Selfless leaders do not have big egos to feed or carefully crafted public personas to defend. They pursue a lifelong calling of service. As the philosopher Paul Ricoeur (1969, p. 349) would say: "[B]eyond the desert of criticism they wish to be called again." Such leaders are well aware of the fact that they swam across the river of complexity and self-enhancement only to discover a new route of childlike simplicity on the other side. No, they are not blind to the tough, day-to-day challenges of leadership, or deaf to the questions facing our fast changing global landscape, but they have embraced a second naïveté which allows them to deal with chaos, complexity and change from the fresh perspectives of curiosity and honesty. In this sense, quoting Carattini (2013), "true naïveté can thus describe one who shows absence of artificiality or unaffected simplicity of nature, one who has no hidden agendas or duplicitous motives."

Character should never be confused with talent (that is, the possession of certain repeatable skills). Modern-day society blindly celebrates talent over character. Far too easily talents, masked as so-called "résumé virtues," are sold off to the highest bidders in the corporate world. No wonder organisations are "overcrowded" with

marked by deep concentration, a distorted sense of time, and absorption. The person is fully immersed in what $\mathrm{s} /$ he is doing so that temporal concerns such as time, food or even the self are disregarded" (Joubert 2013, pp. 128-129). 
many ambitious individuals who know how to climb the corporate ladder en route to formal leadership and managerial positions, but "understaffed" with characterdriven individuals. The latter are passionate about forging a strong moral ethos in any organisation, one that delivers sustainable outputs while also sustaining the personal growth of others. Character-driven people pull organisations through. When wrong decisions are taken and relationships in the workplace suffer, brute talent will never save the day. Character-based leadership is what is called for then $\ldots$ and always!

\section{Discernment Flows from the Hearts of Selfless Leaders}

Discernment is not simply another useful tool in the ever-expanding toolkit of leaders to make their organisations more profitable, streamlined, or desirable. Discernment is a gift, but also a learned ability to think, desire, know, feel, choose and do what is right for the present moment, and to influence future circumstances for the welfare and common good of others. It is the habitual ability to read "the signs of the times" wisely and to act thereupon with clarity, wisdom and soberness. In the words of Howard (2000, p. 10), "discernment is a noetic verbal noun ... the term nearly always has something to do with 'knowing'. Terms like 'awareness,' 'interpret,' 'examine,' 'recognize,' all give indication of the activity of discernment being cognitional. Whether the individual of community 'mind' is operative, whether the focus is external or internal, discernment itself refers to a distinguishing which is a process/product of cognition-a kind of 'knowing'."

Discernment should not be confused with that never-ending pressure on the shoulders of leaders of "constantly getting it right." It is not so much decisionand-outcome driven, but rather the outflow of a deepened ability to notice and choose what is the right way of being present and being of service to others in the "everydayness of our lives - those very places we often overlook as important for discernment" (Liebert 2008, p. xi). Linear processes of reasoning alone do not suffice in this instance. A constant interplay of heart and mind is what is needed, one that is influenced by a strong awareness of the social, situational, and immediate contexts within which leaders find themselves.

Discernment cannot be switched on or off at will. It is a way of life, fuelled by a personal commitment to pay attention to the needs of others and to facilitate their growth. Selfless leaders are well aware of the interconnectedness of people. Keen observation, creative thinking, practical wisdom, and openness to the input of others are key components in their discernment-driven leadership arsenal. Their interactions and decisions are never pragmatic, but flow from an inner clarity regarding the right routes to be pursued to the advantage of others. Hence, discernment in their presence is an art, but also a learned ability to align their perceptions and decisions with their inner character, which also aligns with the well-being of others. "Discernment discovers what is the reasonable thing to do by engaging not only in the head but also in the heart. In and around the linear flow of discursive reasoning, 
discernment is an experienced perception involving the back-and-forth, around-andabout movement of intuition, affective sensibility to values, and subtle assessments of the relationships of multiple factors" (Gula 1997, p. 50).

\section{Character-Based Discernment Translated into the Roles of Sages and Editors}

As part of their reading and shaping the culture of their organisations, selfless leaders intuitively know that it is never about individualism versus the group, but about reciprocally facilitating the unique individuality of members of their organisation to give shape to new forms of "belonging." "This is part of the fluid 'leadership dance', or the ability to understand that currently it is about both individuality and the group, about speeding up and slowing down, and solidity and fluidity" (Joubert 2013, p. 130). Selfless leaders have deliberately stepped down as "professional specialists" and "accountants" whose function it is to constantly keep subordinates "accountable." In their new self-understanding as "editors," leaders assist colleagues, subordinates, followers, clients and customers to write (and rewrite!) their own life stories along the lines of selfless service, respect and generosity. Over against dated routes of accountability leadership, where the emphasis is mostly on past performances of subordinates (or the lack thereof!), selfless leaders choose to focus on the potential, abilities, strengths and gifts of people in their organisation and on how to harness them to the best of their abilities, as well as to the advantage of their organisation. Just as any good editor would ensure that an author produces the best possible manuscript by assisting him/her through all the phases of writing and rewriting, selfless leaders assist those within their spheres of leadership to become the best authors of their own and their organisation's stories. During these different phases, the discernment skills of both leaders-as-editors and subordinates-as-authors are sharpened by their interactions and their shared learning experiences.

At the same time, selfless leaders also perceive themselves as sages who are constantly engaged in mastering "the ways and means of planning, managing and understanding a good life" (Baltes and Staudinger 2000, p. 124). Their rich knowledge of what a well-played life in service of others entails, allows them to "deal[ing] successfully and ethically with people, and also with difficult and ambiguous questions" (Baltes and Staudinger 2000, p. 124). They walk their talk by modelling a life of sincerity, respect and generosity. Narcissism, that "inflated sense of selfimportance and grandiosity" (Greaves et al. 2014, p. 341), is never cultivated in their proximity, since they know that it is damaging to personal relationships and the general welfare of others in their organisations. Selfless leaders have sufficient practical wisdom to constantly modify their strategies and plans. They know how to think on their feet and build aeroplanes in mid-air. Uncertainty and chaos do not scare them. As a matter of fact, complexity and ambiguity are conducive to their abilities to discern. 
The very nature and practical application of selfless leaders' gifts and fine-tuned abilities to discern flow from their self-understanding as sages and editors. These roles are the formative lenses through which they view reality, approach others, grow relationships, manage day-to-day business, and so forth. Thus, the operational mode of selfless leaders is a route of wisdom and editorship where good decisions and right choices are determined by, and judged on the merits of how any possible course of action, or any business deal for that matter, would assist others within their sphere of influence to be of service to their organisations, and how they could reach their full human potential during the course of such processes.

\section{Discernment Is Fine-Tuned by a New Sense of "We-ness," or Community}

All processes of discernment should be based on, and measured by actions that facilitate the reshaping of the core of any organisation from a "me to we"-based culture. In this instance, personal motives and selfish options are deliberately set aside in favour of mutually benefitting ones as a non-negotiable core value. In this instance, people are never left adrift in a dangerous sea of subjectivity at the mercy of a single leader who controls the direction of their organisation. Good discernment never takes place in social isolation, or within hierarchically structured contexts. In a world where all are constantly threatened with suffocation by an avalanche of information and a never-ending barrage of choices, discerning leaders are definitely not updated versions of the Lone Ranger or Rambo. They are not "one-man" or "one-woman" bands trying to singlehandedly save or advance their organisations. They surround themselves with wise people. More to the point, they passionately embrace the value of community; hence, they constantly forge strong and positive relationships with others. In order to foster such a healthy discernment culture, people on all levels of responsibility in their organisations are treated with the same dignity and respect. In turn, this embodied value translates into others also being entrusted with a distinct awareness of, and a practical responsibility for the growth of a relationship-based culture, as well as for specific outcomes during the course of decision-making processes. Undoubtedly, "the process of discernment is slow and messy. But it is neither arbitrary nor authoritarian. The same cannot be said for all other methods of decision making" (Johnson 1983, p. 33).

Selfless leaders are tasked not only with displaying an awareness of the talents, character, needs and responsibilities of others, but also with facilitating adequate responses thereto by building platforms for them on which to prosper (cf. also Gabriel 2015). In such environments, discernment is not only about discriminating, determining, deciding or distinguishing between right and wrong, yes and no, or between the best possible course of action, as the word would literally imply. Of course, leaders' rational abilities to think matters through and to apply a healthy dose of common sense and sound reason to day-to-day decision-making activities should 
never be negated. Strategic thinking and good planning are part and parcel of any form of good leadership, but at the same time it must also include a constant willingness and the fine-tuned ability to approach day-to-day challenges from relational angles, which includes constant input from others.

\section{Generosity as Lens}

One of the big mind shifts that selfless leaders have to make, is towards a new understanding of resources and profit as the means with which to serve and not only as treasures to be stockpiled. In other words, generosity is what is called for. Attitudes of "limited good" are never allowed to grow in such contexts. Limited good, as understood by the anthropologist George M. Foster, proposes that all tangible and intangible entities exist in finite quantities. Everything is available in limited amounts or measures, including food, work, property, money, health, and safety to trust and loyalty, although such scarcity is represented "on a continuum in which the poles are 'more limited' and 'less limited"' (Foster 1972, p. 59). "In all limited good contexts, selfless generosity is uncommon, since without reciprocity, any person who takes from others without giving back anything of equal value is considered a thief, and his/her deeds are conceived of as socially destabilising" (Joubert 2013, p. 125-126). However, in selfless leadership contexts, the values of kindness and hospitality are never finite, since numerous stories of service, care, second miles, and so forth disclose the pervasive presence of generosity. Whereas the greedy live by the unspoken rule that for them to have, others should have less, generous people live their lives and do their work in the prosperity of others.

Selfless leaders work constantly at creating a new ethos of generosity in their organisations. They imprint the conviction in others to collectively participate therein, among others by shared affirmations, mutually rewarding interactions, as well as the constant sharing of narratives that reflect the distinct generosity culture of their organisations. Success on their scoreboard is registered in terms of the liberal sharing of resources and knowledge to the benefit of others. In this instance, wealth is measured by the growth in generosity and by a newly found freedom to share and serve responsibly, since this is one of the discernment-based lenses whereby all options are evaluated and all decisions made.

\section{When Criticism Comes. . .}

As a "me to we"-based process that grows in the fertile soil of mutual respect and generosity, discernment should never be confused with low expectations regarding the output and high quality of the work of others. These values can never be compromised, neither should the route of straightforward honesty be set aside when problems and conflicts arise. The opinions of all matter in selfless leadership 
environments, but never at the expense of the greater good of the organisation, the well-being of others, or the responsibilities of the leaders themselves. Clashes of opinion, criticism, and conflict will be a daily reality, but when criticism comes, good leaders will know not to count but to weigh it, and to address it directly.

The biggest dangers in any discernment-based culture is that of the so-called "anxious risk-avoiding leader" and those destabilizing "weakest human links" who have forced themselves into becoming the strongest ones actually! A risk-avoiding leader is someone who is more concerned with "good feelings than progress, someone whose life revolves around the axis of consensus, a 'middler' ..." (Friedman 2007, p. 13). Well-differentiated selfless leaders are not autocrats. They have clarity regarding their leadership calling and goals. They do not get lost in the entrapments of various emotional processes that sometimes swirl about in their organisations. As Friedman (2007, p. 18) notes: "A leader must separate his or her own feelings from that of his or her followers while still remaining connected. Vision is basically an emotional rather than a cerebral phenomenon, depending more on a leader's capacity to deal with anxiety than his or her professional training ..." Such leaders accept responsibility for their own emotional well-being, while not allowing the "weakest human links" in their organisations to hold others captive with their own emotional baggage and selfish agendas-all under the guise of consensus or unity. Safety and certainty do not motivate selfless leaders; rather, new ways of thinking and acting hold the key for them. It is not about trying harder, or doing more of the same, but by reframing questions, changing the nature, value and flow of information, and eliminating previous dichotomies. In this process, selfless leaders refuse to facilitate reactivity, blame displacement, or a quick fix mentality to determine outcomes, even if they have to face conflict, unpopularity and outright rejection.

Good leaders are able to separate themselves from surrounding emotional processes, especially from those negative ones when relationships and/or decisionmaking processes are imaginatively gridlocked. They intuitively know that more thinking or talking about problems will not suffice, neither will any naive accommodating of weakest human links. Within such situations, decisiveness, clear boundaries, a raised threshold for criticism, and persistence in the face of inertial resistance help sidestep toxic forms of anxiety, which is systemic in many corporate cultures at present (cf. Friedman 2007, p. 89).

\section{Fin}

Contrary to popular understandings of discernment as decision and action, or at best as a process that must always lead to the correct tangible results, it actually entails a way of life. Discernment is a never-ending relational and rational process. It is always in progress. It is relational motion, as some of the terms associated with discernment, such as "awareness, examination, interpretation, discovery, decision, response, action" would imply. Thus "discernment can be comprehended in toto as a 
process or act of knowing" (Howard 2000, p. 10), that is, relational insight and knowing. Such leaders constantly embrace their calling of selfless service to others. Their empathetic responsiveness to the feelings, giftedness, abilities and strengths of people does not overrule their abilities to make good decisions and to remain constantly true to their inner selves. Their fine-tuned ability to discern the right paths to follow in planned and unplanned ways create safe spaces and the right contexts for good decisions, relational growth, creativity, the right kind of profitability, and intimate relationships.

\section{Bibliography}

Agha-Jaffar T (2002) Demeter and Persephone: lessons from a myth. McFarland, London

Alok K (2014) Authentic leadership and psychological ownership: investigation of interrelations. LODJ 35(4):266-285

Avolio BJ, Gardner WL (2005) Authentic leadership development: getting to the root of positive forms of leadership. Leadersh Q 16:315-338

Avolio BJ, Walumbwa FO, Weber TJ (2009) Leadership: current theories research and future directions. Annu Rev Psychol 60(1):421-449

Baltes PB, Staudinger UM (2000) Wisdom: a metaheuristic (pragmatic) to orchestrate mind and virtue toward excellence. Am Psychol 55(1):122-136

Brooks D (2015) The road to character. Random House, New York

Caputo JD (1999) Metanoetics: elements of a postmodern Christian philosophy. In: Ambrosio FJ (ed) The question of Christian philosophy today. Fordham University Press, New York, pp 189-224

Carattini J (2013) http://rzim.org/a-slice-of-infinity/second-naivete/. Posted on 17 July 2013

Chan SCH, Mak WM (2014) Transformational leadership: pride in being a follower of the leader and organizational commitment. LODJ 35(8):674-690

Csíkszentmihályi M (1988) The flow experience and its significance for human psychology. In: Csíkszentmihályi M, Csíkszentmihályi IS (eds) Optimal experience: psychological studies of flow in consciousness. Cambridge University Press, Cambridge, pp 15-35

Davenport B (2015) Compassion, suffering and servant-leadership: combining compassion and servant-leadership to respond to suffering. Leadership 11(3):300-315

Foster GM (1972) A second look at limited good. Anthropol Q 45:57-64

Friedman EH (2007) Failure of nerve: leadership in the age of the quick fix. Seabury, New York

Gabriel Y (2015) The caring leader: what followers expect of their leaders and why? Leadership 11 (3):316-334

Greaves CE, Zacher H, McKenna DR (2014) Wisdom and narcissism as predictors of transformational leadership. LODJ 35(4):335-358

Gula RM (1997) Moral discernment. Paulist, New York

Harding N (2014) Reading leadership through Hegel's master/slave dialectic: toward a theory of the powerlessness of the powerful. Leadership 10(4):391-411

Hauerwas S (1975) Character and the Christian life: a study in theological ethics. Trinity University Press, San Antonio

Hauerwas S (1983) 'The peaceable kingdom': a primer in Christian ethics. University of Notre Dame Press, Notre Dame

Hogg MA (2001) A social identity theory of leadership: personality and social psychology. Leadership 5(3):184-200 
Holstad TJ, Korek S, Rigotti T, Mohr G (2013) The relation between transformational leadership and follower emotional strain: the moderating role of professional ambition. Leadership 10 (3):269-288

Howard EB (2000) Affirming the touch of God: a psychological and philosophical exploration of Christian discernment. University Press of America, Lanham

Johnson LT (1983) Scripture and discernment: decision-making in the church. Abingdon, Nashville Joubert SJ (2013) Not by order, nor by dialogue: the metanoetic presence of the Kingdom of God in a fluid new world and church. Acta Theol 33(1):114-134

Karp T (2013) Studying subtle acts of leadership. Leadership 9(1):3-22

Kellerman B (2008) Followership: how followers are creating change and changing leaders. Harvard Business Press, Boston

Liebert E (2008) The way of discernment: spiritual practices for decision-making. Westminster/ John Knox, Louisville

Moore T (2009) Writing in the sand: Jesus and the soul of the Gospels. Hay House, Carlsbad

Ricoeur P (1969) The symbolism of evil (trans: Buchanan E). Beacon, Boston

Sweet L (2004) Summoned to lead. Zondervan, Grand Rapids

Sweet L (2014) The well-played life: when pleasing God doesn't have to be that hard work. Tyndale Momentum, Bonita Springs

Van Dierendonck D, Driehuizen S (2015) Leader's intention to support followers' self-worth. LODJ 36(2):102-119

Vlachoutsicos CA (2011) How to cultivate engaged employees. HBR 89(9):123-126

Wheatley M (2007) Finding our way: leadership for an uncertain time. Berrett-Koehller, San Francisco

Stephan Joubert is an Extraordinary Professor of Contemporary Ecclesiology at The University of the Free State, South Africa, as well as a Research Fellow at Radboud University, Nijmegen, The Netherlands. At the same time he is the editor of ekerk, a large cyberchurch that sends out more than 2.5 million emails to subscribers annually, a church consultant, speaker and author of more than Christian books, three international academic books, and close to 50 academic articles in various journals and books. He has a daily column in Beeld, the largest Afrikaans newspaper, as well as monthly columns in two South African magazines.

Open Access This chapter is licensed under the terms of the Creative Commons Attribution 4.0 International License (http://creativecommons.org/licenses/by/4.0/), which permits use, sharing, adaptation, distribution and reproduction in any medium or format, as long as you give appropriate credit to the original author(s) and the source, provide a link to the Creative Commons licence and indicate if changes were made.

The images or other third party material in this chapter are included in the chapter's Creative Commons licence, unless indicated otherwise in a credit line to the material. If material is not included in the chapter's Creative Commons licence and your intended use is not permitted by statutory regulation or exceeds the permitted use, you will need to obtain permission directly from the copyright holder.

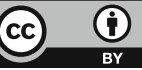

